\title{
ON THE DISTRIBUTION OF SUSPENDED SEDIMENT IN NATURAL RIVERS
}

\author{
By Dr. Eng. Shigeru Tanaka*, C.E. Member and Shūichi Sugimoto**, \\ C.E. Member
}

\section{Synopsis}

Many papers concerning theoretical researches on sediment suspension have been published up to now. These papers have treated the problem of sediment suspension under the way of thinking that the suspended particles in the turbulent flow are to be transported in suspended state by the action of the mixing process of turbulence. And the data heretofore observed concerning the sediment suspension in the flowing water are rather few, because the measurement is rather hard in point of the measuring device and technique. The usual theories concerning this problem have been induced on the basis of the assumption that the mixing length of turbulence is constant at any point throughout the whole water depth, and the assumption that the velocity-distribution of the flow obeys the logarithmic law.

The writers published the new theory ${ }^{1)}$ concerning the velocity-distribution from the original way of thinking that the mixing length of turbulence varies with the position above the bed, and have established a new theory by pushing forward this idea to the distribution of sediment concentration. And furthermore, the writers deviced a simple river-water sampler and have obtained some data concerning the sediment concentration by performing samplings at a gauging station of the River Yodo several times, and examined the adaptability of the writers' theory by properly determining the constants used in the writers' formulas.

\section{Introduction}

The writers published the theoretical formulas representing the velocity-distribution of turbulent flow based on the consideration that the mixing-length of turbulence is a function of the ratio of the normally measured distance from the bottom-surface to any point to the total water-depth measured normally to the bottom.

Recently they have payed their attention to the point that the suspended particles take similar movement to that of water particles according to the turbulence of the flow.

\section{Theory}

For simplicity's sake, they assume that the flow is two-dimensional and turbulent, and furthermore, the particle-size of the suspended materials is uniform.

Now they take the straight channel; and in this case, they represent the center-line of the riverbed-plane as a straight line, take a point on the line as an origin, take the center-line running in the flow direction as $x$-axis, the straight line upward perpendicular to $x$-axis as $z$-axis, the water-depth measured normally to the bed as $h$, the weight of suspended particles per unit-volume of the streaming water at position $z$ above the bed as $m$, the Austausch coefficient as $\eta$, the settling velocity of particles in still water as $w_{0}$, the mixing length of turbulence as $l$, and the coefficient of kinematic viscosity of the flowing fluid as $\nu$.

Then, the following relation exists :

$$
\frac{\partial}{\partial z}\left(\eta \frac{\partial m}{\partial z}\right)=-w_{0} \frac{\partial m}{\partial z}
$$

Integrating both side-terms of this equation, there exists the relation :

$$
\eta \frac{d m}{d z}=-w_{0} m
$$

Accordingly, the following relation is obtained:

* Professor, Department of Civil Engineering, Faculty of Eng., University of Kōbe

** Assistant, 


$$
\frac{d m}{m}=-\frac{w_{0}}{\eta} d z=-\frac{w_{0} h}{\eta} d \xi
$$

where

$$
\xi=z / h \text {. }
$$

The Austausch coefficient $\eta$ is given as follows :

$$
\eta=l^{2}\left|\frac{d u}{d z}\right| \text {. }
$$

This relation is given when the suspended particles take just the same movement as the motion of fluid particles in turbulent flow, showing the fluctuations made by turbulence. But, here, it is a more general way of thinking that the suspended particles do not move exactly in the same way as the fluid particles move fluctuated by turbulence. Accordingly, under such way of thinking, the Austausch coefficient $\eta_{s}$ of suspended particles affected by the fluctuations caused by turbulence is expressible in the following relation, using the equivalent mixing-length of turbulence of these particles $l_{s}$ :

$$
\eta_{s}=l^{2}\left|\frac{d u}{d z}\right| .
$$

Now, if we assume the $l_{s}$ is proportionate to the $l$, we have :

$$
l_{s}=K l \text {. }
$$

where $K$ is a constant.

This relation has the same content as the opinion that the sediment transfer coefficient $\varepsilon_{s}$ is similar but not necessarily equal to the turbulent momentum transfer coefficient $\varepsilon_{m}$ stated by V.A. Vanoni $^{2)}$ and H.M. Ismail ${ }^{3)}$. Now, the mixing-length of turbulence $l$ of the flowing fluid can be expressed in the following form introduced by the writers, as reported in their lately published paper ${ }^{1)}$ :

$$
l / h=\mathrm{A}\left(1-e^{-B \xi}\right) \text {. }
$$

And also, $d u / d z$ was induced by the writers in the following form :

$$
\frac{d u}{d z}=\frac{d u}{h d \xi}=\frac{1}{2 h} \frac{1}{(l / h)^{2}}\left[\frac{\nu}{h}+\frac{l}{h} \sqrt{1-\xi} \sqrt{4 g h \sin \theta}\right] \text {. }
$$

Substitution of Eqs. (5), (7) into Eq. (4), gives

$$
\eta_{s}=\frac{K^{2}}{2} h\left[\frac{\nu}{h}+\frac{l}{h} \sqrt{1-\xi} \sqrt{4 g h \sin \theta}\right] .
$$

Substitution of Eq. ( 8 ) into Eq. $\left(2^{\prime}\right)$ (adopting $\eta_{s}$ instead of $\eta$ ), gives

$$
\frac{d m}{m}=-\frac{2 w_{0}}{K^{2}} \cdot \frac{d \xi}{[\nu / \mathrm{h}+(l / h) \sqrt{1-\xi} \sqrt{4 g h \sin \theta}]} .
$$

Integrating this equation, and determining the integration's constant by using the notation $m_{0}$ which indicates the weight of suspended particles per unit-volume of the fluid at the stream-bed, there exists the relation:

$$
\frac{m}{m_{0}}=\exp \left[\frac{-2 w_{0}}{K^{2}} \int_{0}^{\xi} \frac{d \xi}{[\nu / h+(l / h) \sqrt{1-\xi} / \overline{4 g h \sin \theta}]}\right] .
$$

Now, putting $\nu / h \doteqdot 0$, Eq. ( 9 ) is given in the following simplified form :

$$
\frac{m}{m_{0}}=\exp \left[-\frac{w_{0}}{K^{2}} \frac{1}{\sqrt{g h \sin \theta}} \int_{0}^{\xi} \frac{d \xi}{(l / h) \sqrt{1-\xi}}\right] \text {. }
$$

\section{Observations and Analysis of the Results Obtained}

A. Principle of Analysis for the Observed Results Obtained

The analysis of the observed results is performed by the writers in the following order :

(1) On the basis of the measured velocity-distribution, the value of $l / h$ (ratio of the mixinglength of turbulence to the flow-depth) is to be analyzed by using Eq. (6) and Eq. (7).

(2) Substituting the thus obtained value of $l / h$ into Eq. (10), and furthermore, using the actually-measured data concerning the concentration-distribution of suspended particles, we determine the values of $w_{0} / K^{2}$ and $\mathrm{m}_{0}$ by trial and error method.

Referring to the sand particles suspended in the unit-volume of the flowing water, the grain-size 
differs widely from grain to grain, and the amount by weight is very small; accordingly, it is very hard to determine the settling-velocity in the still water of the collected particles. The value of the proportional constant $K$ is almost impossible to be determined in advance, due to the difficulty of observation. The value of $m_{0}$, viz. the weight of sand-particles suspended in the unit-volume of flowing water at the stream bed, is unable to be actually measured notwithstanding of being ideally conceivable.

Thus, it is very hard to measure these values of $w_{0}, K$, and $m_{0}$, beforehand; so we are compelled to determine these values by using the observed results of velocity and concentration distributions of suspended particles.

B. Measuring Apparatus and Method of Measurement

a. Sampling Apparatus

The sampler of flowing water which was deviced by the writers is composed of 16 short pieces of a vinyl-chloride pipe, $16 \mathrm{~mm}$. in inner dia. and $22 \mathrm{~mm}$. in outer dia., 11 pcs. $10 \mathrm{~cm}$. long and 5 pes. 5 $\mathrm{cm}$. long, at either end of which a fine-pitched screw is cut, and 15 short collars connect the said pieces. At the mid-point of the length of each piece, $10 \mathrm{~mm}$. dia hole is bored through the wall, and these bored 16 holes should be arranged on a straight line; they are plugged with rubber-plugs at ordinary case where the sampler is out of use. On the top end of this sampler a brass cup-tube is put, which is used to connet the sampler-pipe with a small suction-pump by means of a short rubber hose; and at the lower end a brass-ferrule is equipped. (See Fig. 1)

Fig. 1 Sketch of the Writers' Sampler

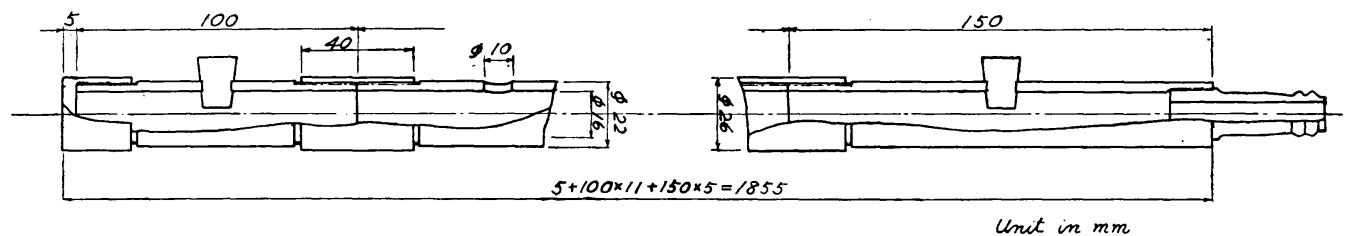

When the writers collect water-samples by using this sampler, the following process is taken; firstly, they take out the rubber-plug at a certain desired depth from where a water sample is to be taken; secondly, they set the sampler vertically in the stream-flow facing the holes toward the upstream side, held firmly with the aid of a specially-devised splice-steel-bar; and thirdly, they pump up the flowing water with suspended particles contained, from the desired depth at a suction-velocity corresponding to the flow-velocity by working the said suction-pump properly, and pour the water into. one-liter polyethylene-bottle.

In the laboratory they separate the suspended particles from the river-water by filtering the water through filter-paper, then they dry up the particles in a hot-drier and weigh them.

\section{b. Current-Meter}

In order to measure the flow-velocity, the writers used the Price Electric Current Meter.

C. Observed Results and their Analysis

The writers selected the Hirakata Gauging Station established by the Ministry of Construction on Fig. 2 Cross-section of the Flow at the Measurement Station of the River Yodo

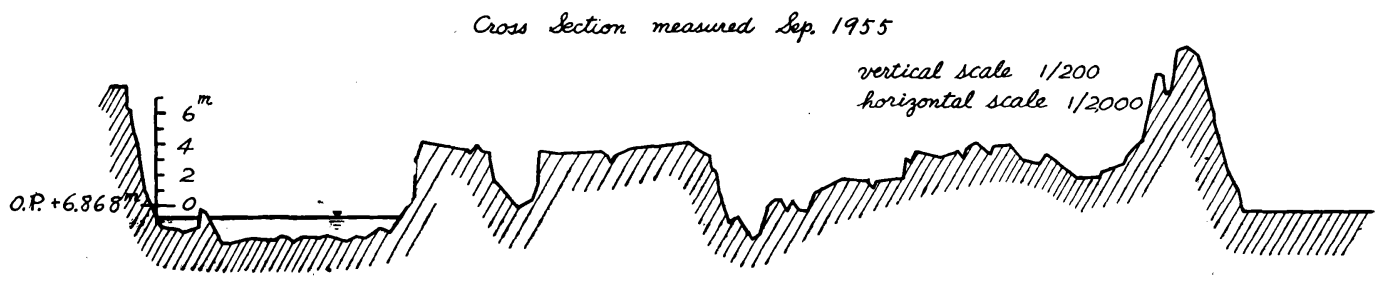

O.P \pm 0 
the left bank-side of the River Yodo as the actual measurement station, and made observations three times. The cross-section of the stream at the site is shown in Fig. 2.

The observed results of the velocity-distribution and concentration-distribution of the sedimentsuspension are plotted in Fig. 3-Fig. 5, the former in $\bigcirc$ marks and the latter in $\Delta$ marks.

Fig. 3 Observed Data and Calculated Curves representing Velocity-Distribution, Concentration-Distribution and $l / h$-Distribution versus $z$

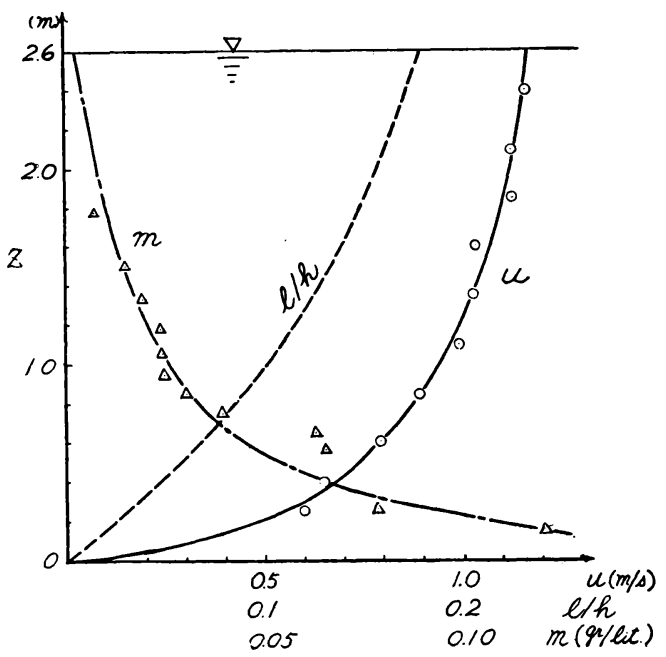

Fig. 4 Same as Above

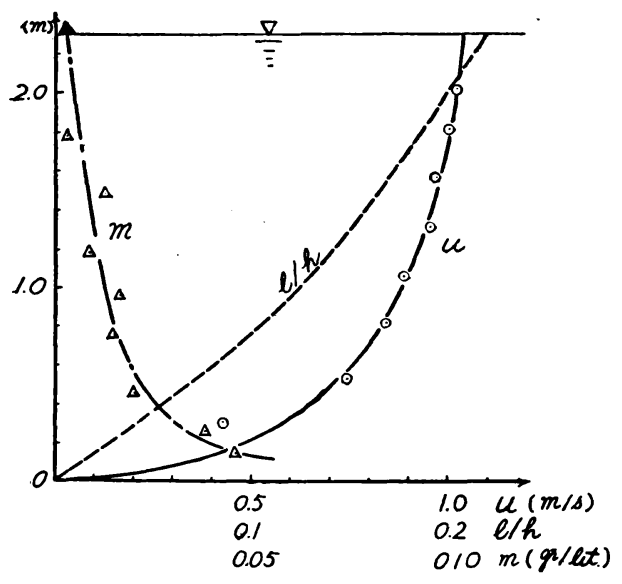

Fig. 5 Same as Above

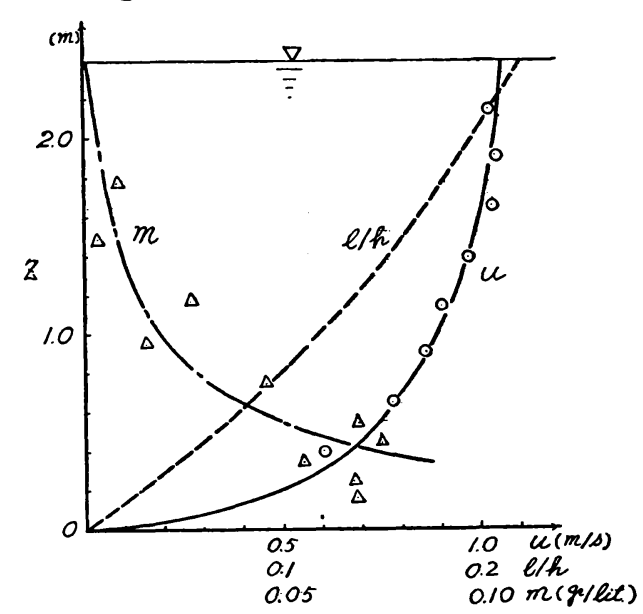

As the first step of the analysis, the writers determined the values of $A$ and $B$ in Eq. ( 6 ) concerning the mixing-length of turbulence, by using Eq. (7) and the observed data of the velocitydistribution; and secondly, they took up the observed data of sediment-concentration and examined if the observed results showed good accordance with the theoretical ones calculated by using Eq. (10) by determining the values of $m_{0}$ and $w_{0} / K^{2}$. Thus, they obtained the theoretical curves representing the velocity-distribution and the distribution of sediment-concentration, each being represented in full-line and in chain-line. The $l / h$ versus the height above the stream-bottom is shown in dotted line in each of the figures. These curves are shown in Fig. 3-Fig. 5.

The values of $A, B, m_{0}$ and $w_{0} / K^{2}$ are shown in Table-1.

The writers also picked up one of the observed data) which had been taken by the members of the Public Works Reserch Institute of the Ministry of Construction at the River Hii flowing into Lake Shinji in Shimane Prefecture, near Bridge Inoue $10.4 \mathrm{~km}$. upstream from the river mouth, and analyzed 
Table-1 Values of $A, B, m_{0}$ and $w_{0} / K^{2}$

\begin{tabular}{c|c|c|c|c|c|c|c}
\hline Measurement & $A$ & $B$ & $\begin{array}{c}m_{0} \\
\mathrm{gr} / \text { liter }\end{array}$ & $\begin{array}{c}w_{0} / K^{2} \\
\mathrm{~m} / \mathrm{sec}\end{array}$ & $\begin{array}{c}\text { Water } \\
\text { temp. } \\
{ }^{\circ} \mathrm{C}\end{array}$ & $\begin{array}{c}\text { Measurement position } \\
\text { fr. the left bank } \\
\mathrm{m}\end{array}$ & Date of observation \\
\hline I & 0.2300 & 1.5 & 0.4137 & 0.02337 & 18.5 & 130 & Oct. 10, 1956 \\
II & 0.3463 & 1.0 & 0.1174 & 0.01751 & 6.5 & 70 & Dec. 19, 1956 \\
III & 0.3473 & 1.0 & 1.5520 & 0.03590 & 6.5 & 70 & Jan. 28, 1957 \\
\hline
\end{tabular}

it on the basis of writers' theory. The station of their observation and the observed data are shown in their Investigation Report.

The velocity-distribution and the distribution of sediment-concentration of the observed results are shown in $\bigcirc$ marks and in $\triangle$ marks, respectively, in Fig. 6.

Fig. 6 Observed Data and Calculated Curves representing Velocity-Distribution, Concentration-Distribution and $l / h$-Distribution versus $z$

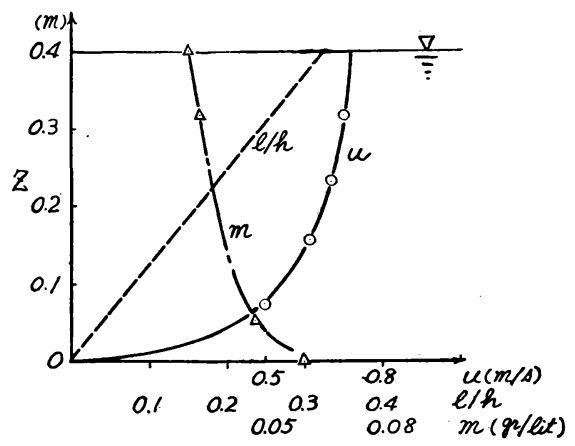

The theoretical values of $\mathrm{u}, l / h$, and $m$ versus $z$ are shown in full-line, dotted-line and chain-line, respectively, in the same way as the above-stated one. The values of $A, B, m_{0}$ and $w_{0} / K^{2}$ are shown in Table-2.

Table-2 Values of $A, B, m_{0}$ and $w_{0} / K^{2}$

\begin{tabular}{c|c|c|c|c}
\hline$A$ & $B$ & $\begin{array}{c}m_{0} \\
\mathrm{gr} / \mathrm{liter}\end{array}$ & $\begin{array}{c}w_{0} / K^{2} \\
\mathrm{~m} / \mathrm{sec}\end{array}$ & Date of observation \\
\hline 3.420 & 0.1 & 0.06971 & 0.003445 & March 17, 1951 \\
\hline
\end{tabular}

\section{Conclusion}

It has been proved that the theory proposed by the writers shows fairly good results by this research. The number of data heretofore reported concerning sediment-concentration in natural streams or rivers are rather few, much less such available data as are provided with good curves both of velocitydistribution and of sediment-concentration distribution.

The velocity-distribution curves observed in narrow streams or channels show that the position of the max. velocity is situated at some distance below the water surface, being affected by the side-bank friction. On the other hand, the curves observed in wider river show that the position of the max. velocity is situated at the water hurface. The theory published by the writers is fairly applicable to the latter case, $i$. e. the case where the effect of side-banks or walls have no influence.

In any of the river flows, it is almost impossible to measure the velocity and sediment-concentration distributions at high water; so, we are necessarily forced to make measurement at ordinary water, and accordingly the concentration is so light that the weighing is accompanied by much difficulty. The writers are intending to make many more observations in natural rivers in order to confirm the adaptability of the above-stated theory here proposed as to the sediment-concentration in river-flow.

\section{Acknowledgments}

The writers wish to acknowledge the instructive advices given this work by Dr. Eng. Tōjirō Ishi- 
hara in the University of Kyoto, the kind assistance of the staff of the Yodogawa Improvement Office of the Ministry of Construction and the facility afforded by Dr. Hideo Kikkawa and other staff of the Public Works Research Institute of the Ministry of Construction.

\section{References}

1) Shigeru Tanaka \& Shüichi Sugimoto: On the Velocity-Distribution and the Mixing Length Peculiar to the Thin Super-Critical Flow Streaming on a Rough Bed, Trans. of J.S.C.E., No. 35, pp. 39-47, June, 1956.

2) V.A. Vanoni : Transportation of Suspended Sediment by Water, Trans. of A.S.C.E., Vol. 111, pp. 67-133, 1946.

3) H.M. Ismail : Turbulent Transfer Mechanism and Suspended Sediment in Closed Channels, Trans. of A.S.C.E., Vol. 117, pp. 409-446, 1952.

4) H. Kikkawa \& Y. Sone: Investigation Report concerning the Fundamental Problems in order to establish the Improvement Planning of the River Hii, Technical Report of Public Works Research Institute of the Ministry of Construction, Vol. 85-3, July, 1952.

(昭.32.9.13)

昭和 33 年 7 月 1 日 印刷 昭和 33 年 7 月 10 日 発行

編集兼発行者

印刷所

\section{土木学会論交集第57号}

定価 120 円（空 20 円）

東京都新宿区四谷 1 丁目 中 川 一 美

東京都港区赤坂溜池 $\mathbf{5}$ 番地株式会社技 報 堂

発行所袿界土木学会 